\title{
Quality of life research: A case for combining photo-elicitation with interpretative phenomenological analysis
}

\author{
Amy Burton, Melanie Hughes \& Robert C. Dempsey
}

Staffordshire Centre for Psychological Research \& Centre for Health Psychology, School of Psychology, Sport and Exercise, Staffordshire University, UK

Corresponding Author: Amy Burton, Faculty of Health Sciences, School of Psychology Sport and Exercise, Staffordshire University, Stoke on Trent, ST4 2DF, UK (e-mail: amy.burton@staffs.ac.uk, Tel: 01782 294661).

\section{About the authors:}

Amy Burton (BSc, MSc, PhD) is a Health Psychologist and Senior Lecturer at Staffordshire University

Melanie Hughes (BSc) was a MSc Health Psychology Student at Staffordshire University

Robert Dempsey (BSc, PhD) is a Lecturer in Psychology in the School of Psychology, Sport and Exercise at Staffordshire University.

Disclosure Statement:

The authors declare no conflicts of interest. 


\section{Quality of life research: A case for combining photo-elicitation with interpretative phenomenological analysis}

In this paper we provide practical and theoretical discussion of the use of two complementary research methods to explore quality of life. We present a case example of the use of photo-elicitation alongside Interpretative Phenomenological Analysis and use examples from our research with people living with paraplegia and chronic pain to demonstrate how these methods can be combined to provide a participant-led understanding of QoL. This discussion includes consideration of practical and ethical issues relevant to others wishing to combine these research methods. Furthermore, we highlight some of the potential practical and therapeutic opportunities provided by the approach through an illustration of how photographs work to enhance self-reflection and promote hermeneutic sense making.

Keywords: Quality of Life, Interpretative Phenomenological Analysis, Photo Elicitation, Paraplegia, Chronic Pain 


\section{Introduction}

1.1 Approaches to researching quality of life

Quality of life (QoL) is a common outcome measure in health research, intervention evaluation, and clinical trials (Fitzpatrick et al., 1992). However, the concept of QoL is rarely defined with clarity and there is a lack of consensus about its meaning (Bowling \& Windsor, 2001). Ambiguity has led to debates and disagreements regarding measurement and how to identify which components contribute to this multidimensional concept (Holmes, 2005). Traditionally QoL has been measured using selfreport surveys (see Bowling, 2005 for a comprehensive review of QoL measures for a range of health conditions), however, critiques regarding the way these tools constrain responses and fail to explore subjective interpretations and life contexts are common (Blaxter, 1990; Donovan, Frankel, \& Eyles, 1993; Mallinson, 2002). Furthermore, these measures frequently define QoL in medical or functional terms and therefore fail to capture what constitutes QoL for individuals in a patient-centred way (Carr \& Higginson, 2001).

In order to move away from QoL definitions restricted to medical needs and function, broader understandings informed by concepts derived from individual experience are needed (Bowling \& Windsor, 2001; Gabriel \& Bowling, 2004). Qualitative methods are one way to overcome the constraints of survey approaches and investigate these broader QoL concepts. For example, Interpretative Phenomenological Analysis (Smith et al., 2009) is well suited to this endeavour as researchers begin the process with a general area of interest rather than a predetermined hypothesis (Langdridge, 2007). In QoL research this flexibility facilitates a contextualised picture of wellbeing grounded in participants' own interpretations of their experience (Burton, Shaw, \& Gibson, 2015). 
1.2 Interpretative Phenomenological Analysis

Interpretative Phenomenological Analysis (IPA; Smith et al., 2009) is a qualitative approach with roots in phenomenological philosophy and psychology (Langdridge, 2007). The key aim of IPA research is to uncover how individuals experience a particular phenomenon and what meaning this experience holds for those individuals (Smith et al., 2009).

Edmund Husserl's (Husserl, [1900] 1970) early transcendental phenomenology sought to identify essential core structures of experience or 'essences' through the exploration of phenomena as they appear to consciousness. Husserl ([1900] 1970) argued that in order to capture these 'essences' researchers must 'bracket' or 'transcend' prior assumptions. However, existential phenomenologist, Martin Heidegger ([1927] 1962) was critical of this stance and proposed that 'bracketing' could never be fully achieved as our observations are always made from somewhere and we must instead focus on understanding existence as lived (Larkin, Watts, \& Clifton, 2006). According to Heidegger ([1927] 1962), we cannot help but interpret experience in light of our foreconceptions (prior experiences, assumptions, and knowledge); elements of experience appear to us in our consciousness and, as they do so, they may have visible or hidden meanings. Our interpretations of new experiences are therefore an opportunity to reflect upon our fore-conceptions, resulting in experience of 'reality' being cyclical process of interpretation and reflexivity. In line with this proposal researchers using IPA acknowledge a 'double hermeneutic' (Smith \& Osborn, 2008) in which the researcher is attempting to make sense of the participants interpretations of their experience.

Researchers employing IPA therefore recognise that data collection takes place within a specific context, time and place and that interview data represents a coconstruction of meanings (Smith et al., 2009). This co-construction can be understood 
by considering Gadamer's (1975) ‘horizons'; all individuals have pre-conceptions, beliefs, and past experiences which make up their horizon of understanding. We are only able to make sense of and interpret the world within these horizons and as researchers, we engage with the horizons of our participants. When horizons overlap, it is possible for the researcher to gain understanding of the life-world of the participant and for the participant to understand the perspective of the researcher.

While quantitative research takes a nomothetic stance to knowledge production in order to make general claims about populations as a whole, IPA instead employs an idiographic approach committed to understanding the particular experience of individuals (Langdridge, 2007). Understanding can be developed through exploring the whole and the parts; for example, a single word can make sense in isolation, however the word is given meaning within the whole sentence, and without each individual word, the meaning of the whole sentence is lost. Therefore, an understanding of individual experiences alongside nomothetic population data is essential for developing a clear picture of a phenomenon such as QoL. This is particularly important for developing an understanding of the meaning of QoL in homogenous groups such as those with specific health conditions whose idiosyncratic experiences are not well captured by generic population measures.

1.3 The problem with interviews and focus groups

In-depth interviews are the most common data collection methods used in IPA studies (Smith, 2015) and qualitative QoL research alike; as illustrated by a number of recent reviews in this area (e.g. Connell, Brazier, O’Cathain, Lloyd-Jones, \& Paisley, 2012; Jackson \& Roberts, 2015; Topcu, Buchanan, Aubeeluck, \& Garip, 2016). Though giving more flexibility to participants than self-report questionnaires, interviews create 
an inevitable power imbalance in the researcher-researched relationship (Potter \& Hepburn, 2005; Yardley, 2000). As researchers we choose the topic, devise the interview schedule, and decide where and when to probe and elicit more information (Kvale \& Brinkmann, 2009). Therefore, to facilitate a more participant-led understanding of concepts, such as QoL, there is a need to explore alternative methods of 'giving voice' (Larkin et al., 2006) to the participant experience.

\subsection{Photo-elicitation}

One alternative approach to using researcher-devised topic schedules is with visual stimuli to guide research interviews. Some research has explored the use of drawing as a stimuli for IPA interviews (Kirkham, Smith, \& Havsteen-Franklin, 2015; Shinebourne \& Smith, 2010) however this, to some extent, relies on artistic creativity of the participant and adds an additional layer of interpretation as researchers must interpret the participant's creations which may not be easily accessible within researchers 'horizon' (Gadamer, 1975) of understanding. Another, lesser used, opportunity for creative data production is photography. Photography is less reliant on the participants' artistic creativity as images of physical and everyday objects can be captured. These images are more accessible and recognisable within researchers' 'horizons' of experience; therefore facilitating the interpretation process and development of shared understanding of experience.

The term 'photo-elicitation' was coined by American anthropological researcher John Collier in the mid-1950's (Collier, 1957). Collier employed visual imagery to engage participants in the research process, arguing that photography could have a compelling effect upon the informant through its ability to prod latent memory and stimulate and release emotional statements. Collier's original approach to creating the 
photograph stimuli was researcher led; the research team took a selection of images of industrial locations and used these as stimuli, alongside a structured interview, to explore how participants felt about their work. Photo-elicitation techniques have since been employed as an alternative approach to data collection in which participants create the images and take control of the research agenda (Del Busso, 2011; Sandhu, Ives, Birchwood, \& Upthegrove, 2013).

The photo-elicitation method advanced in the realm of health research through Caroline Wang and Ann Burris' (1997) Photovoice. This collaborative approach asks participants to document community health resources and needs through photography. Community photo sharing sessions are then used to prompt discussion of the images and create a space and opportunity for marginalised voices to be heard (Wang \& Burris, 1997). This participatory approach uses photographs as a means to enable people to think critically about issues in their community and provides opportunities to influence and promote change at community and policy levels (Wang \& Redwood-Jones, 2001).

Participatory methods such as Photovoice and photo-elicitation ensure that participant experiences are central to the knowledge created (Letts, 2003). Whilst the collection of photographs has previously been employed alongside interpretative phenomenological analysis (Ramalho, Lachal, Bucher-Maluschke, Moro, \& RevahLevy, 2016; e.g. Rodham, Boxell, McCabe, Cockburn, \& Waller, 2012) to our knowledge there has been no exploration of the value of combining these techniques in the exploration of QoL.

\section{Aim}

In this paper we reflect on the practical and theoretical considerations required in the combination of photo-elicitation (Collier, 1957) and interpretative phenomenological 
analysis (IPA; Smith et al., 2009) when exploring QoL. We illustrate our reflections through specific examples from our study exploring the QoL experiences of people living with paraplegia and chronic pain. In this paper we do not intend to present the themes resulting from our IPA study as this detail is available elsewhere (authors, under review). Instead, we explore how our chosen methods can work to uncover meanings regarding QoL and the advantages and disadvantages of using this combined approach. For the purposes of context and transparency, we begin by giving an overview of how participants were recruited and data were collected, additional detail is available in our results paper (authors, under review).

\section{Method}

\subsection{The participants}

Ethical approval for this research was obtained from a University Ethics Panel. In line with Smith, Flowers and Larkin's (2009) recommendations for sample size in IPA research, six adults with paraplegia and self-reported chronic pain (1 male, 5 female) were recruited. These were the first participants to volunteer using opportunity sampling through online forums and a United Kingdom (UK) university mailing list. Participants who saw the advertisement contacted the research team via email to express their interest in taking part. Consent forms and information sheets were distributed and returned via email. Each participant provided descriptive data relating to their age, gender, length of time living with paraplegia, length of time experiencing chronic pain and marital status. Participants were aged 32-64 years (Mean: 49.5, SD: 10.61). All were White British, four were in a marital relationship, one was cohabiting and one was single. 


\subsection{Photo-elicitation process}

We combined elements of both photo-elicitation (Collier, 1957) and Photovoice (Wang \& Burris, 1997) in the research process. As we were interested in understanding the QoL experiences of our participants, rather than facilitating community and policy change, our approach was to develop interview discussions led by images of experience created by the participants themselves.

Participants were asked to spend seven days taking photographs of things that they felt gave their life quality or reduced their QoL. To ensure that understanding was grounded in participant experience, the information sheet stated that participation would "involve you taking photographs of things that you feel give you quality of life and things that you feel take away quality of life" and no further definition of QoL was provided. At the end of the week participants were invited to choose the six photographs they felt best represented their QoL experiences. Photographs were labelled 1-6 and sent to the researcher via email and a convenient day and time was arranged for interview.

Due to the geographical variability of participant's homes, and the mobility challenges experienced by our participants, telephone interviews were used. While this approach limits access to non-verbal cues that aid rapport during data collection (Kvale \& Brinkmann, 2009) telephone interviews have been successfully employed in several IPA studies (e.g. Cox \& Faithfull, 2015; Turner, Barlow, \& Ilbery, 2002; Whitehurst \& Rowlands, 2016). The interviews began by asking the participant to describe their background (e.g 'tell me a little about yourself?', 'tell me a little about your disability'). Questioning was purposefully generic to allow participants to discuss the importance of each photograph in turn (e.g. 'If we start with the first photograph, can you tell me why you chose this picture', 'What does it represent in terms of your quality of life?' 'How did you feel when you were taking the photograph?' 'What is the particular importance 
of this picture?'). This approach helped us to avoid questions biased by researcher assumptions about the nature of the experience. Both the researcher and the participant had a copy of the photographs in front of them to facilitate discussion of the images. Interviews ranged from 45 minutes to one hour in duration, participants chose their own pseudonyms, and all interviews were transcribed verbatim for analysis.

\subsection{Analysis}

Analysis was conducted following the IPA guidance of Smith, Flowers \& Larkin (2009). As discussed in our introduction, QoL is a challenging concept to define, and the participants' narratives therefore guided us in order to develop our understanding of the concepts central to QoL for this group. We began by attending to each individual case and line-by-line annotations were made in one margin of the transcript identifying descriptive, linguistic and conceptual features in the text (Smith et al., 2009). Transcripts were then re-read to identify emergent themes, which were grouped to form clusters of related themes. Finally comparisons across cases were made and master themes were identified (a full account of the findings of this analysis is available elsewhere; Authors, under review).

For this paper, the first author further reviewed the transcripts and extracted all examples in which participants referred to the research process. From these examples, extracts have been selected and are discussed alongside theoretical literature in order to illustrate the value of combining photo-elicitation with IPA.

\section{Combining photo-elicitation with interpretative phenomenological analysis}

In this section, we use extracts from our participant interviews to illustrate how the combination of photo-elicitation with IPA can benefit both researchers and participants. 
We begin by illustrating how access to participant photographs aided our ability to engage with our participants experiential 'horizons' (Gadamer, 1975) and facilitated interpretative phenomenological analysis through ensuring participant-led understandings of QoL. We then go on to highlight benefits for our participants in terms of how the process of taking and reflecting on photographs functioned to enable reflection on issues central to QoL and facilitated hermeneutic sense-making. Finally, we highlight the potential therapeutic benefits of this approach.

3.1 Expanding researcher 'horizons' and gaining an 'insider's perspective' IPA aims to provide an 'insider's perspective' (Smith, 1996) on an experience. In order to do this researchers need to get close to the data and attempt to understand and identify with the 'horizons' (Gadamer, 1975) of our participants. We found that the opportunity to discuss an image of an actual event in the lives of our participants helped us to take one step closer to the experiential 'horizon' of our participants and facilitate our ability to develop an 'insider's perspective'. For example, the overwhelming number of medications taken by Sylvie could be illustrated in the photograph more powerfully than in a description alone:

Interviewer: So you mention, and I can see from the picture, there is a lot going on with your medication, can you explain a little further about what the medication does for you please?

Sylvie: Pain relief erm (.) blood pressure, erm mostly its pain relief. The bulk of it is made up of different pain relief that I have to take together, if I leave one of them off ...so let's for example although I can't think off the top of my head but if I have four medications to take and I leave just one of them off then the three I have taken are non-void so no bloody use really (laughs). 
This photograph helped us to understand Sylvie's account of how it was possible to make errors when taking her medications given the evidence of the vast number she needed to take. Without the photograph, it may have been difficult to understand how a person could make an error with a medication that was so vital to ensuring pain levels remained livable. The image helped us identify with how overwhelming management of such a complex medication regime could be and empathise with Sylvie's frustration about when mistakes were made, therefore aiding our interpretation of her account.

For Nigel a picture of his wife's bedroom helped us to understand the story of how the onset of chronic pain, in addition to paraplegia, had drastically altered his dayto-day life:

This just tells my life story of home life really, departed and lonely as I used to sleep in this bed with my wife. Many many years this was my bedroom too and now it isn't and never will be because doctors won't grant me a proper lift. Taking this photo really gripped my heart ya know, cos looking through a camera and thinking about the reasons for taking it, really got to me cos it made me realise how much things have changed for not just me but my wife as well. [...] [sleeping downstairs is] good and bad really, good cos ya know it helps me with my disability, my illnesses and my pain management. I have to be lifted everywhere and to be able to just slide into bed without messing around in bloody stair lifts and wheelchairs eases that side for me. Erm, the fact my wife doesn't have to mess around lugging me here there and everywhere is good because she doesn't need that. The bad thing is when I am in excruciating pain, there's no one by my side to just reach out to [...] If I become really poorly who is going know until it is too late? My wife has tried to sleep down here on the chair but it doesn't help her so I have told her she must go bed, but it scares me cos there's no one. (Nigel)

Access to this image helped us to visualise how the move to sleeping downstairs was both good and bad for Nigel's marital relationship and his QoL, once again 
facilitating our interpretation of the account. Nigel revealed how the process of taking this photograph had been a powerful emotional experience and prompted active reflection on the journey to his current living situation; illustrating the value for both Nigel's sense making and our own.

Physical changes in sleeping location and health were intertwined with Nigel's emotional responses to a changing marital relationship; the account was filled with guilt and responsibility for burdening his wife with caring responsibilities. Nigel had paraplegia for all of his life, but the worsening of his chronic pain condition had forced a gradual reduction in his independence. Nigel's martial relationship had changed from equal partners to what he perceived as a carer and cared-for partnership, and the change to downstairs sleeping had in some ways helped him to rebalance this. However, this was at the expense of proximity, comfort and support that had eased Nigel's health fears and been beneficial for his QoL. This account illustrates a complex and contradictory account of QoL facilitators and barriers, which would be impossible to access through survey approaches. Furthermore, Nigel's engagement in the photography process helped him and us to access reflection on living circumstances in a way that may not have been uncovered using a traditional interview schedule.

\subsection{Participant-led understandings of QoL}

As illustrated above, the use of photographs encourages detailed contextualised stories regarding participants' daily experiences (Radley \& Taylor, 2003). In our research, the use of photo-elicitation empowered our participants to take control of the nature of the data. The freedom to discuss and reflect on recent personal experiences created space to express elements of their lived experience from their own perspective. 
Taking the photograph left me feeling sad because it took me back to the day when I was with [my great nephew] and he gave me this teddy bear. I was surrounded by family, [my great nephew] was just a huge bubble of fun. Going back to taking the photograph made me want that day over again, I wish I had more days like that because I can feel like the former me [...] I have the bear in reality but so many emotions came through when I was taking the photo that it made me realise how lucky I am to have a such a young child to adore me like he does. I didn't get that before. Ya know, kids are very impressionable ya know and well I don't look normal do I? So to have him accept me is a dream. I just wish the rest of society could do that (Emily-Ray)

Emily-Ray had taken a photograph of a teddy bear on her sideboard that reminded her of a specific member of her family. Family were very important to EmilyRay and experiences and memories of happy times with them was important for her QoL. Through discussion of this photograph, we gained insight into bittersweet memories; Emily-Ray expressed a feeling of sadness as she reflected on how it was only when her great nephew was present that she could feel like the 'former' her. This distinction between "me now" and "me then" came out frequently in the accounts of our participants. It illustrated the implications for the acquisition of disability and pain to alter perceptions of identity. Once again, the photograph prompted our participant to explore the meaning behind the image they had chosen and we saw a shift, through reflection, to a revelation about how much she is loved by her great nephew and joy at these moments of feeling accepted in an often-unwelcoming world. Emily-Ray touched upon how she felt she was viewed differently to an able-bodied person and reflected on the idea that as her great-nephew had not been exposed to societal prejudice she felt his perception of her was not tainted by the presence of her wheelchair. In this way, the photograph prompted Emily-Ray to make sense of, and find meaning in, this complex 
experience and understand the value of her relationship with her great nephew for maintaining her QoL.

We felt that the most valuable contribution made by the use of the photoelicitation method was that it empowered our participants to lead and control the definition of QoL. While there were shared experiences and challenges (discussed in our paper reporting the full findings; Authors, under review) there were also unique examples that may have been lost or missed in a researcher-led interview. Notable discussions include the importance of companion animals (Angie), a golden locket containing a picture of a deceased relative (Elsa) and a selection of ornaments given as gifts by family and friends (Sylvie). These examples held unique importance for understanding the experience of individual participants, a vital component to ensure the idiographic focus of IPA research. Furthermore, these examples illustrate dimensions of QoL (e.g. isolation, friendships and companionships, happy memories) that would not be captured in traditional questionnaires based on restrictive functional definitions of QoL.

3.3 Prompting self-reflection and hermeneutic sense-making

'Photographs can jolt subjects into a new awareness of their social existence. As someone considers this new framing of taken-for-granted experiences they are able to deconstruct their own phenomenological assumptions.' (Harper, 2002) Photographs were an opportunity for our participants to both capture the 'in the moment' experience and to reflect on and understand their experiences through discussion with the researcher. The photographs therefore helped us to encourage enhanced sense-making and reflection. 
Seeing reality in the photo has made me think how life has become since my injury. I took a lot for granted as you do, so the photo is good because now I can draw myself into the photo and it kind of makes me re-evaluate things a little. (Angie)

Angie reflected on a photograph of her wheelchair in her garage. This image represented a barrier to QoL; the challenge of getting up the few steps from her garage to her home. This reflection prompted Angie to go beyond this experience and uncovered her thoughts about the difficulty of finding a home that was suited to her needs. A garage was essential as it meant that, regardless of the weather, Angie could get in and out of her car without the concern of falling. Once inside her home, Angie's house was all on one level, but to get there she needed to pull herself up into the house using a rail. This was one of the many things that Angie felt she had taken for granted before her accident and was now a frustration. The image helped Angie to convey this challenge and present her perspective on the way the world is built for people without disability.

For Angie the opportunity to look at the photograph encouraged the comparison her life prior to her accident to now. It helped Angie to make sense of QoL in terms of overcoming obstacles and gave her a new sense of perspective about the changes resulting from her disability. Angie's account illustrates her understanding of how choice about living environments could empower individuals with paraplegia to enhance their QoL. Similarly, another participant, Sylvie, explained how home modification had improved her QoL.

Until the photo was taken I didn't really give much thought ...to me the kitchen was there it was put there and it's been helpful but because I was asked to take this photograph and to think about it I have looked at in more depth so it's got a lot of meaning to me now (Sylvie) 
For Sylvie a photograph of her newly adapted kitchen helped her to reflect on the value of home modifications. Like Angie's garage, Sylvie's old kitchen was an example of an environment built for someone without a disability; the cupboards were too high for her to reach and the sink was inaccessible as Sylvie couldn't put her chair underneath, having to wash up facing side on to the sink. Sylvie also needed assistance when cooking, as she could not reach the worktops, usually using her knee to rest chopping boards and frequently breaking plates and other kitchen items.

The newly adapted kitchen meant that Sylvie no longer had to rely on her family to help, cupboards had been amended and new features had been added to make the kitchen work for he; she could push her chair under the sink to wash up and could make use of the work surfaces. This for Sylvie gave her freedom, independence and QoL and the experience of taking and looking back at the photograph highlighted this for her, clarifying how important this change had been and giving her new insight and understanding in relation to issues that improved her QoL.

3.4 Potential therapeutic value of participation

Giving participants the opportunity to talk about their experiences within the context of research interviews is often reported to have therapeutic benefits (B. L. Murray, 2003; M. Murray, 2003). This was the case for our participants, but furthermore, the inclusion of photographs as a long-term reminder of their contribution to the research project was also something participants found valuable.

Maybe I can look back and remember this interview and be glad I took part (Angie)

I reckon I'll just file [this picture] as a reminder of my input to this study. (Donna) 
The photographs could be kept by the participant as a memento of their contribution; reminding them of both the interview process but also of something good that they had done in relation to helping build an understanding of the lives of people like them. The experience had potential to help others in the future but also, as explained above, helped them piece together and make sense of their own experiences. This is in line with past research that has illustrated that participants express appreciation of involvement in research even when issues discussed can be personally upsetting; valuing the opportunity to talk through their experiences (Scott, Valery, Boyle, \& Bain, 2002) and to potentially help understand and develop support for others (Owen, Gooding, Dempsey, \& Jones, 2016).

As previously discussed, the opportunity to talk about the meaning behind photographs during the research interviews helped the participants to make sense of their experiences and develop a new perspective on how the issues affected their QoL. There is strong evidence that creative techniques can have important benefits in therapeutic settings (Fleet, 2015; Fleet, Burton, Reeves, \& Das Gupta, 2016; Gladding, 2014). However, the use of photographs in therapy settings, while potentially common practice, is rarely discussed in research. Our findings illustrate the benefits of photographs to help individuals make sense of their experiences and come to terms with both positive and negative impacts on their QoL.

\section{Discussion}

In this paper, we have provided a practical illustration of how the use of photoelicitation combined with interpretative phenomenological analysis can have benefits for both researchers and research participants when exploring QoL. Photo-elicitation enables participants to take control of the research agenda and provides a medium 
through which self-reflection and hermeneutic sense making can be facilitated.

Furthermore participant led understandings of QoL can be of benefit to the researcher, providing rich data and additional resources to enable the development of shared 'horizons' (Gadamer, 1975) of understanding.

In line with the theoretical basis of interpretative phenomenological analysis (Smith et al., 2009), the benefit of photo-elicitation was the production of an idiographic, nuanced and detailed understanding of each individual participants' QoL experience. Like Boden and Eatough (2014), who advocate the use of multi-modal visual and verbal approaches to uncover both reflective and pre-reflective understandings of phenomena, we found that this approach to data collection enabled us to build comprehensive understanding of our participants' lived experience. Boden and Eatough (2014) propose that imagery provides the opportunity to try out alternative avenues for presenting experience when words are inadequate or difficult to find, providing a bridge between the felt-sense of lived-experience and the fullest possible verbal account of that experience. Harper (2002) provides some insight into how this is achieved, proposing that images evoke deeper elements of human consciousness than words. This is achieved through stimulation of visual processes in the brain that are evolutionarily older than processes for verbal information and therefore facilitates deeper reflection and interpretation than a traditional verbal-only interviews (Harper, 2002).

Traditionally QoL has been understood to relate to a network of interwoven constructs and domains (Bowling, 2005) rather than an essence found within a single encounter. Our examples illustrate that enhanced reflection is the mechanism through which photo-elicitation can uncover the link between the felt-sense of lived experience and full verbal accounts of QoL. Photo-elicitation has proven to be suited to uncovering 
the nuance of this experience through highlighting detail regarding how and why different encounters and day-to-day experiences contribute to an overall sense of QoL within individual lifeworlds (Husserl, 1970). Combining images with in-depth interviews facilitated reflection on the creation of, and meaning behind, the images and encouraged 'thick description' (Ponterotto, 2006) enabling researchers and readers to get a sense of the cognitive and emotional state of each participant. The use of a photo elicitation method therefore fits with cognitive psychological models of autobiographical memory, whereby mental imagery is considered key to the recollection and reconstruction of memories of personally experienced events rich in sensory detail and vividness (Conway \& Pleydell-Pearce, 2000).

Photo-elicitation is well suited to phenomenological approaches that advocate the importance of hermeneutics and the interpretative nature of research activity both on the part of the participant and the researcher (e.g. IPA; Smith et al., 2009; Hermeneutic Phenomenology; van Manen, 1990). The approach may be less suited to descriptive phenomenological work aiming to capture the typical essence or structure of an experience. For example, Giorgi's descriptive phenomenology (Giorgi, 1975; Giorgi \& Giorgi, 2013) which minimises and generalise personalised and idiographic elements of experience (Finlay, 2009). Data for this form of analysis requires concrete descriptions of lived experience and therefore individual participants' reflective commentary would present a potential barrier and additional 'noise' in the analytical process (See Finlay, 2009 , for a detailed discussion of the methodological differences between phenomenological research approaches).

Despite the benefits for interpretative phenomenological researchers, it is important to acknowledge that the combination of these two approaches also creates challenges and to highlight practical and ethical considerations for researchers wishing 
to use these methods in their own work. Firstly, when planning this research we had to think carefully about consent and anonymity in relation to the images produced by our participants in line with ethical requirements for human research (The British Psychological Society, 2009, 2014). We felt that by appearing in a photograph to be shared with us, an individual would be providing data for analysis beyond the observation of public behaviour in situations "in which persons being studied would reasonably expect to be observed by strangers" (The British Psychological Society, 2009, p13). By this definition, these individuals had the right to know how their image would be used and therefore would become participants in the research process necessitating the need for informed consent. We felt the inclusion of additional consent taking procedures would be a cumbersome burden for our participants and therefore considered this by asking our participants not to include other people in their photographs in order to prevent the inclusion of non-consenting individuals within the research.

Secondly, despite the provision of information sheets and consent forms some participants struggled to understand what was required of them. The instruction to take photographs throughout a week was a more complex task than engaging in a one-on-one interview and caused some confusion. Despite guidance in the information sheet, some participants needed reassurance on which locations they were permitted to take photographs in, and others captured images of friends or family members. Understandably, these individuals were central to our participants' QoL experiences. However, we wanted to ensure that anonymity of these non-consenting individuals was preserved and therefore advised participants that these images would not be used in the interviews and immediately destroyed any images of non-consenting individuals we received. This was our approach to the process, however other researchers may wish to 
include photographs within their analysis or publications and consideration of the ethical constraints in relation to images of human subjects would need to be carefully considered.

These issues meant that explaining the research process to ensure "clear, unambiguous informed consent” (The British Psychological Society, 2014, p9) required more researcher time than was originally anticipated and is something to be considered when planning future research of this type. In particular, the second author spent time reassuring participants that what they were doing was 'right'. Furthermore, our work has illustrated that there is a need to consider participant burden and ensure sufficient time for those with disabilities or health problems to complete photography tasks. We found that this took longer than anticipated, something that has been reported by other researchers employing similar approaches (Booth \& Booth, 2003). While we only required a small number of images, in practice some participants took 5-6 weeks to complete the photograph stage of the research and needed regular gentle prompting. The interviewer was understanding of this due to the nature of the participants' physical disabilities, but it was a great challenge within the project to obtain the photographs and complete the work within the time available. This issue requires careful consideration at the point of research design and development and future use of this approach should ensure realistic timescales.

These issues may be problematic as the use of photographs, and in particular Photovoice, is often advocated as engagement tool for marginalized and vulnerable groups (Aldridge, 2007; Booth \& Booth, 2003). While the approach breaks down some of the barriers and power differentials inherent in traditional interview research allowing these groups to find a voice within the research literature (Wang \& Burris, 1997), 
practical challenges in the implementation of the approach were apparent in our research.

As already discussed, photo elicitation promotes and facilitates reflection, and therefore may be a particularly valuable approach for individuals for whom reflective capacity is reduced due to symptoms, medications, disabilities, or otherwise. However, the use of creative methods with these groups is also not without potential challenges. In addition to those we have already raised for our physically disabled participants, intellectual issues may also reduce the ability to select photographs for consideration and individuals without speech or the ability to sign may require consideration of alternative communication strategies (Boxall \& Ralph, 2009). However, restriction of research to participants for whom these approaches do not present a challenge only serves to marginalise groups who are already noticeably absent from research and future work should explore strategies to overcome these issues and enhance participation wherever possible.

\section{Conclusion}

In this worked example of the use of photo-elicitation alongside IPA, we have illustrated our reflections on a number of challenges and benefits experienced when using this approach. It was not our aim to prescribe how these methods should be used but instead to share our own experiences and choices in the hope that these can inform others in their endeavour to complete future work of this type.

Despite some challenges, the benefits experienced for both participant and researcher illustrate that this approach can make important contributions to our understanding of QoL. Photo-elicitation provides an innovative method that allows participants to enjoy the research process and feel empowered to lead research into 
areas that represent personal constructions of QoL. The ability of the approach to enhance reflection illustrates the value of photo-elicitation and future research should explore the use of this technique for uncovering the accounts of individuals with inhibited reflective capacity. For these groups the approach may facilitate opportunities to contribute to and participate in research.

Additionally, the use of photographs within research interviews can act as a therapeutic device facilitating opportunities to reflect on and make sense of experiences, and come to new understandings about the factors that hinder or contribute to QoL. In line with this, it is clear that the opportunities and implications for the use of photography in therapeutic work should be further explored and evaluated. This is particularly relevant as a move towards a digital age and the growing use of tablets and smartphones facilitates the ability to collect and incorporate day-to-day images within therapeutic practice (Lowenthal, 2013). Using more readily available mobile photography may facilitate the collection of images over longer time periods, particularly where there is interest in exploring changes over the course of therapy.

In summary, this work has illustrated how photographs help participants to make sense of their experiences providing both detailed in-depth accounts for analysis while also exhibiting the potential for photography to play an important role in therapeutic settings.

\section{References}

Aldridge, J. (2007). Picture this: The use of participatory photographic research methods with people with learning disabilities. Disability and Society, 22, 1-17.

Blaxter, M. (1990). Health and lifestyles. London: Routledge.

Boden, Z., \& Eatough, V. (2014). Understanding more fully: A multimodal 
hermeneutic-phenomenological approach. Qualitative Research in Psychology, 11, 37-41. https://doi.org/10.1080/14780887.2013.853854

Booth, T., \& Booth, W. (2003). In the frame: photovoice and mothers with learning difficulties. Disability \& Society, 18(4), 431-442.

Bowling, A. (2005). Measuring health: A review of quality of life measurement scales (3rd Editio). Maidenhead: Open University Press; England.

Bowling, A., \& Windsor, J. (2001). Towards the good life: A population survey of dimensions of quality of life. Journal of Happiness Studies, 2, 55-81.

Boxall, K., \& Ralph, S. (2009). Research ethics and the use of visual images in research with people with intellectual disability. Journal of Intellectual and Developmental Disability., 34(1), 45-54. https://doi.org/10.1080/13668250802688306

Burton, A. E., Shaw, R. L., \& Gibson, J. M. (2015). Living together with age-related macular degeneration: An interpretative phenomenological analysis of sensemaking within a dyadic relationship. Journal of Health Psychology, 20(10), 12851295.

Carr, A. J., \& Higginson, I. J. (2001). Are quality of life measures patient centred? BMJ (Clinical Research Ed.), 322(7298), 1357-1360.

https://doi.org/10.1136/bmj.322.7298.1357

Collier, J. (1957). Photography in Anthropology: A Report on Two Experiments. American Anthropologist, 59, 843-859.

Connell, J., Brazier, J., O’Cathain, A., Lloyd-Jones, M., \& Paisley, S. (2012). Quality of life of people with mental health problems: a synthesis of qualitative research. Health and Quality of Life Outcomes, 10(1), 138. https://doi.org/10.1186/1477$7525-10-138$ 
Conway, M. A., \& Pleydell-Pearce, C. W. (2000). The construction of autobiographical memories in the self-memory system. Psychological Review, 107, 261-288.

Cox, A., \& Faithfull, S. (2015). Aiding a reassertion of self: a qualitative study of the views and experiences of women with ovarian cancer receiving long-term nurseled telephone follow-up. Supportive Care in Cancer, 23(8), 2357-2364. https://doi.org/10.1007/s00520-014-2578-4

Del Busso, L. (2011). Using photographs to explore the embodiment of pleasure in everyday life. In P. Reavey (Ed.), Visual Methods in Psychology: Using and Interpreting Image in Qualitative Research. (pp. 43-55). London: Routledge.

Donovan, J. L., Frankel, S. J., \& Eyles, J. D. (1993). Assessing the need for health status measures. Journal of Epidemiology and Community Health, 47, 158-162.

Finlay, L. (2009). Debating Phenomenological Research Methods. Phenomenology \& Practice, 3(1), 6-25. https://doi.org/10.1007/978-94-6091-834-6_2

Fitzpatrick, R., Fletcher, A., Gore, S., Jones, D., Spiegelhalter, D., \& Cox, D. (1992). Quality of life measures in health care. I: Applications and issues in assessment. BMJ (Clinical Research Ed.), 305(6861), 1074-7. https://doi.org/10.1002/em.20581

Fleet, D. (2015). Ways of Working Beyond Words. Private Practice, Spring, 14-17.

Fleet, D., Burton, A., Reeves, A., \& Das Gupta, M. P. (2016). A case for taking the dual role of counsellor-researcher in qualitative research. Qualitative Research in Psychology, 13(4), 328-346. https://doi.org/10.1080/14780887.2016.1205694

Gabriel, Z., \& Bowling, A. (2004). Quality of life from the perspectives of older people. Ageing and Society, 24, 675-691.

Gadamer, H. G. (1975). Truth and method. New York, NY: Seabury. 
Giorgi, A. (1975). An application of phenomenological method in psychology. In A. Giorgi, C. Fischer \& E. Murray (Eds.), Duquesne studies in phenomenological psychology: Volume II (pp. 72-79). In A. Giorgi, C. Fischer, \& E. Murray (Eds.), Duquesne studies in phenomenological psychology: Volume II (pp. 72-29). Pittsburgh, PA: Duquesne UP.

Giorgi, A., \& Giorgi, B. (2013). Phenomenological Psychology. In C. Willig \& W. Stainton Rogers (Eds.), The sage handbook of qualitative research in psychology (pp. 165-179). London: Sage.

Gladding, S. T. (2014). The creative arts in counseling. (4th ed.). US: John Wiley \& Sons Inc; US.

Harper, D. (2002). Talking about pictures: A case for photo elicitation. Visual Studies, $17(1), 13-26$.

Holmes, S. (2005). Assessing the quality of life-reality or impossible dream? International Journal of Nursing Studies, 24, 493-501.

Husserl, E. (1970). Logical investigation. (Trans J. N. Findlay). New York, NY: Humanities Press.

Jackson, L. J., \& Roberts, T. E. (2015). Conceptualising quality of life outcomes for women participating in testing for sexually transmitted infections: A systematic review and meta-synthesis of qualitative research. Social Science \& Medicine, 143, 162-70. https://doi.org/10.1016/j.socscimed.2015.08.048

Kirkham, J. A., Smith, J. A., \& Havsteen-Franklin, D. (2015). Painting pain: an interpretative phenomenological analysis of representations of living with chronic pain. Health Psychology: Official Journal of the Division of Health Psychology, American Psychological Association, 34(4), 398-406. 
Kvale, S., \& Brinkmann, S. (2009). Interviews: Learning the Craft of Qualitative Research Interviewing. London: Sage.

Langdridge, D. (2007). Phenomenological psychology: Theory, research and method. Harlow: Prentice Hall.

Larkin, M., Watts, S., \& Clifton, E. (2006). Giving voice and making sense in interpretative phenomenological analysis. Qualitative Research in Psychology, 3(2), 102-120. https://doi.org/10.1191/1478088706qp062oa

Letts, L. (2003). Occupational therapy and participatory research: A partnership worth pursuing. American Journal of Occupational Therapy, 57, 77-87.

Lowenthal, D. (Ed.). (2013). Phototherapy and Therapeutic Photography in a Digital Age. Hove: Routledge.

Mallinson, S. (2002). Listening to respondents: A qualitative assessment of the ShortForm 36 Health Status Questionnaire. Social Science and Medicine, 54(1), 11-21. https://doi.org/10.1016/S0277-9536(01)00003-X

Murray, B. L. (2003). Qualitative research interviews: therapeutic benefits for the participants. Journal of Psychiatric and Mental Health Nursing, 10(2), 233-236. https://doi.org/10.1046/j.1365-2850.2003.00553.x

Murray, M. (2003). Narrative Psychology. In J. Smith (Ed.), Qualitative Psychology: A Practical Guide to Research Methods (pp. 111-132). London: Sage.

Owen, R., Gooding, P., Dempsey, R., \& Jones, S. (2016). The experience of participation in suicide research from the perspective of individuals with bipolar disorder. Journal of Nervous and Mental Disease, 204(11), 840-844.

Ponterotto, J. G. (2006). Brief note on the origins, evolution, and meaning of the qualitative research concept “ thick description .” The Qualitative Report, 11(3), 
538-549. Retrieved from http://www.nova.edu/ssss/QR/QR11-3/ponterotto.pdf

Potter, J., \& Hepburn, A. (2005). Qualitative interviews in psychology: Problems and pitfalls. Qualitative Research in Psychology, 2, 281-307.

Radley, A., \& Taylor, D. (2003). Images of recovery: a photo-elicitation study on a hospital ward. Qualitative Health Research, 13(1), 77-99.

Ramalho, J. de A. M., Lachal, J., Bucher-Maluschke, J. S. N. F., Moro, M. R., \& Revah-Levy, A. (2016). A qualitative study of the role of food in family relationships: An insight into the families of Brazilian obese adolescents using photo elicitation. Appetite, 96, 539-545. https://doi.org/10.1016/j.appet.2015.10.023

Rodham, K., Boxell, E., McCabe, C., Cockburn, M., \& Waller, E. (2012). Transitioning from a hospital rehabilitation programme to home: Exploring the expereinces of people with complex regional pain syndrome. Psychology and Health, 27(10), $1150-1165$.

Sandhu, A., Ives, J., Birchwood, M., \& Upthegrove, R. (2013). The subjective experience and phenomenology of depression following first episode psychosis: A qualitative study using photo-elicitation. Journal of Affective Disorders, 149, 166174.

Scott, D. A., Valery, P. C., Boyle, F. M., \& Bain, C. J. (2002). Does research into sensitive areas do harm? Experiences of research participation after a child's diagnosis with Ewing's sarcoma, 177, 507-510.

Shinebourne, P., \& Smith, J. A. (2010). Images of addiction and recovery: An interpretative phenomenological analysis of the experience of addiction and recovery as expressed in visual images. Drugs: Education, Prevention and Policy, 
18(5), 313-322. https://doi.org/10.3109/09687637.2010.514621

Smith, J. A. (1996). Beyond the divide between cognition and discourse: using interpretative phenomenological analysis in health psychology. Psychology and Health, 11, 261-271.

Smith, J. A. (2015). Qualitative Psychology: A practical guide to research methods (3rd ed.). London: Sage.

Smith, J. A., Flowers, P., \& Larkin, M. (2009). Interpretative Phenomenological Analysis: Theory, Method and Research. London: SAGE Publications.

Smith, J. A., \& Osborn, M. (2008). Interpretative phenomenological analysis. In J. A. Smith (Ed.), Qualitative Psychology: A Practical Guide to Research Methods. (2nd ed.). London: Sage.

The British Psychological Society. (2009). The Code of Ethics and Conduct. Leicester: BPS.

The British Psychological Society. (2014). Code of Human Research Ethics. Leicester: BPS.

Topcu, G., Buchanan, H., Aubeeluck, A., \& Garip, G. (2016). Caregiving in Multiple Sclerosis and Quality of Life: A Meta-synthesis of Qualitative Research. Psychology \& Health, 31(6), 693-710. https://doi.org/DOI:10.1080/08870446.2016.1139112

Turner, A., Barlow, J., \& Ilbery, B. (2002). Play Hurt, Live Hurt: Living with and Managing Osteoarthritis from the Perspective of Ex-professional Footballers. Journal of Health Psychology, 7(3), 285-301. https://doi.org/10.1177/1359105302007003222 van Manen, M. (1990). Researching lived expereince: Human science for an action 
sensitive pedagogy. Albany, NY: SUNY Press.

Wang, C., \& Burris, M. A. (1997). Photovoice: Concept, methodology, and use for participatory needs assessment. Health Education \& Behavior, 24, 369-387.

Wang, C., \& Redwood-Jones, Y. A. (2001). Photovoice Ethics: Perspectives from Flint Photovoice. Health Education \& Behavior, 28(5), 560-572. https://doi.org/10.1177/109019810102800504

Whitehurst, J. L., \& Rowlands, J. (2016). Helping palliative care healthcare professionals get the most out of mentoring in a low-income country: a qualitative study. BMC Palliative Care, 15(1), 90. https://doi.org/10.1186/s12904-016-0164-x

Yardley, L. (2000). Dilemmas in qualitative health research. Psychology \& Health, 15(2), 215-228. 


\begin{tabular}{|c|c|c|c|c|c|c|}
\hline Pseudonym & Age & Gender & $\begin{array}{l}\text { Cause of } \\
\text { Paraplegia }\end{array}$ & $\begin{array}{l}\text { Years with } \\
\text { paraplegia }\end{array}$ & $\begin{array}{l}\text { Years with } \\
\text { Chronic } \\
\text { Pain }\end{array}$ & $\begin{array}{l}\text { Marital } \\
\text { Status }\end{array}$ \\
\hline Angie & 34 & Female & $\begin{array}{l}\text { Cheerleading } \\
\text { accident }\end{array}$ & 14 (age 20) & 2 & Partner \\
\hline Donna & 48 & Female & $\begin{array}{l}\text { Motorbike } \\
\text { accident }\end{array}$ & 18 (age 30$)$ & 12 & Married \\
\hline Elsa & 41 & Female & $\begin{array}{l}\text { Motorbike } \\
\text { accident }\end{array}$ & 15 (age 26) & 10 & Married \\
\hline Emily-Ray & 49 & Female & $\begin{array}{l}\text { Horse-riding } \\
\text { accident }\end{array}$ & 32 (age 17) & 7 & Single \\
\hline Nigel & 62 & Male & $\begin{array}{l}\text { From birth } \\
\text { (hereditary) }\end{array}$ & 62 (birth) & 42 & Married \\
\hline Sylvie & 58 & Female & $\begin{array}{l}\text { Childhood } \\
\text { accident (bike) }\end{array}$ & 53 (age 5) & 5 & Married \\
\hline
\end{tabular}

